\title{
Sealing versus partial caries removal in primary molars: a randomized clinical trial
}

\author{
Daniela Hesse ${ }^{1 *}$, Clarissa Calil Bonifácio² ${ }^{2}$ Fausto Medeiros Mendes ${ }^{1}$, Mariana Minatel Braga', \\ José Carlos Pettorossi Imparato ${ }^{1}$ and Daniela Prócida Raggio ${ }^{1}$
}

\begin{abstract}
Background: The resin-based pit and fissure sealant is considered a successful tool in caries prevention, however there is a growing evidence of its use in controlling already established caries in posterior teeth. The aim of this clinical trial is to verify the efficacy of pit and fissure sealants in arresting dentinal caries lesions compared to partial excavation and restorative treatment in primary molar teeth.

Methods: Thirty six patients with occlusal cavitated primary molar reaching outer half of dentin were selected. The patients were randomly allocated into two groups: sealant application (experimental group $-n=17$ ) and restoration with composite resin (control group - $n=19$ ). Clinical and radiograph evaluation were performed after 6,12 and 18 months. The chi-square test was used to verify the distribution of characteristics variables of the sample among the groups. The survival rate of treatments was evaluated using Kaplan-Meier survival and log-rank test. Fisher's Exact and logistic regression tests were calculated in each evaluation period $(a=5 \%)$.
\end{abstract}

Results: The control group showed significantly better clinical survival after 18 months ( $p=0.0025)$. In both groups, no caries progression was registered on the radiographic evaluations.

Conclusions: Sealing had similar efficacy in the arrestment of caries progression of cavitated occlusal lesions compared to partial excavation of the lesions, even though the frequency of re-treatments was significantly higher in sealed lesions.

Trial registration: Registro Brasileiro de Ensaios Clínicos (ReBEC): RBR-9kkv53

Keywords: Pit and fissure sealants, Dental caries, Primary teeth, Caries lesion, Partially excavation

\section{Background}

Dental caries is a disease with identified etiology and able to be prevented and controlled [1,2]. It is established that caries development is dependent on the biofilm stagnation area on the dental surface. The metabolic activity in dental plaque is the fuel for caries lesion development and the demineralization occurs as a result of this dynamic process [3]. Therefore, a lesion could be arrested by controlling the biofilm on its surface. However, it is more difficult to enhance and disorganize the biofilm in cavitated lesions, even with careful brushing.

Conventional caries lesions management is usually based on operative procedures to re-establish the surface integrity and enable efficient dental plaque removal [3]. Resin-based

\footnotetext{
*Correspondence: dhesse@usp.br

'Orthodontics and Pediatric Dentistry Department, Dental School, University of São Paulo - USP, Av. Lineu Prestes, São Paulo, SP 2227, Brazil

Full list of author information is available at the end of the article
}

sealants were developed to be applied on the occlusal surfaces susceptible to the development of caries lesions, covering the pits and fissures, creating a layer that avoids the retention of food debris and biofilm in these areas, thus preventing the development of caries lesions [4]. There is a strong evidence of the benefits in using sealants as a preventive approach [2,5-7], and studies have been conducted using sealants for the treatment of caries lesions, with results showing that while the sealant remains adhered to the tooth surface, the lesion is arrested [8-11].

There is considerable evidence that the complete removal of infected dentin is not required to achieve caries lesions arrestment [12], therefore the partial removal of caries lesion and restoration with composite resin can be considered good clinical practice [13]. Indeed, this statement is supported by the results of clinical trials, which reported success rates of $100 \%$ after 6 months [14] and 3 years of follow-up [11]. The application of resin-based sealants 
have also shown high success rates, ranging from $80 \%$ to [11,15] $94.8 \%$ [4] after 2 and 3-year follow-up in permanent molars and $61 \%[16,17]$ to $88 \%$ [18] after 2 and 3 years of assessment in primary molars.

The caries-preventive effect of pit and fissure sealants has been intensively studied in the literature and shows strong evidence of its effectiveness [2,5,19]. However, the indication for applying occlusal sealants seems to be shifting from primary prevention to a therapeutic decision for caries management in enamel and outer half of the dentin lesions [20]. The fact that caries lesion can be arrested by sealing the cavity is not recent. Since the 1970 s some researches highlighted this fact. The idea of sealing caries lesions without invasive intervention possibly began with Handelman et al. [21]. Since then, a large number of studies have been developed by using the resin-based sealants over caries and the results suggest that the lesion is arrested [8-11,21-25].

To the best of our knowledge there is one study that has investigated the application of resin-based fissure sealant for the treatment of caries lesions in primary molars [18], but they have worked only with non-cavitated lesions. Since there are several difficulties in the management of children's behavior during conventional restorative treatment, sealing dentinal caries lesions in primary teeth can be an interesting and less invasive alternative. The hypothesis tested was that more caries progression is expected with the application of a resin-based pit and fissure sealant compared to partial excavation and restorative treatment. Therefore, the aim of this clinical study is to verify the efficacy of pit and fissure sealants in arresting dentinal caries lesions compared to partial excavation and restorative treatment in primary molar teeth.

\section{Methods}

\section{Participants and recruitment}

After approval from the Local Research Ethics Committee (protocol 204/05 - School of Dentistry, University of São Paulo), thirty six children seeking dental treatment at the School of Dentistry of University of São Paulo were selected and written consent was obtained from all legal guardians. The study was performed during the period of 2007 until 2011. The children were aged 4 to 9 years old (mean age $=7$ ). Sample power was calculated (using an $\alpha$ error of 5\%) and resulted in 0.9 .

The children were selected after clinical and radiographic examination by the operator (DH), who was trained and calibrated for the caries assessment according to ICDAS scores [26] and for caries activity according to the visual-tactile criteria of Nyvad [27]. Lesions with a matt and rough surface were scored active, whereas lesions with a shiny and smooth surface were scored inactive. During the first visit, the children had the surfaces of teeth professionally cleaned with pumice and rotating brushes, and air-dried before assessment of caries lesion presence [26] and activity [27]. Also, bitewing radiographs were taken during this first appointment, in order to evaluate the deepness of the caries lesion.

The caries experience of patients included in this study was classified as above average $($ mean $=6.0)$ according to age-related dmft values (decayed, missed, filled teeth) for Brazilians [28].

Only children with good general health, and at least one primary molar with occlusal active caries lesion [27] classified as ICDAS score 5 [26], with an opening not wider than $3 \mathrm{~mm}$ diameter in the enamel, measured with a millimeter probe, and with no pain history were included in this study. Radiographically, the lesion should reach the dentin, but be maximally limited to the half way through this substrate. Moreover, the selected tooth could not have any restoration or caries lesions in surfaces that could interfere with the study proposal.

Baseline bitewing radiographs were taken using bitewing holders (Indusbello, Londrina, Brazil). The equipment used was a Spectro 70X (Dabi Atlante, Ribeirão Preto, Brazil) with $70 \mathrm{kV}, 8 \mathrm{~mA}$ and the exposure time was 0.4 seconds. The films used were speed group E (Eastman Kodak Co., New York, USA) and they were manually developed using standard processing times.

The patients were randomly allocated into two groups with the use of a list of random numbers generated by computer:

- Experimental Group: pit and fissure resin-based sealant application, without removing caries tissue $(n=17)$.

- Control Group: restorative treatment with composite resin, after partial dentinal caries removal $(n=19)$.

All treatments were performed by one operator properly trained and helped by a dental assistant. The operator was a final-year undergraduate dental student who was previously trained to perform both techniques used in this study. A training week was included to give the operator the opportunity to familiarize herself with the sealants application and restorative technique prior to the start of the operative phase.

\section{Intervention}

Only one tooth per child was included in the research. If more than one cavity met the inclusion criteria, one of them was randomly chosen. The other caries lesions in the selected children were treated by the researchers, who also provided information regarding diet and oral hygiene instructions.

The teeth from the experimental group were sealed according to the following protocol: (a) occlusal surface cleaned with pumice; (b) local anesthesia applied; (c) rubber dam applied; (d) 37\% phosphoric acid placed on 
occlusal surface for 15 seconds; (e) surface rinsed and dried; (f) adhesive system (Adper Single Bond 2, $3 \mathrm{M}$ ESPE, Saint Paul, USA) applied, following the manufacturer's instructions and light cured for 20 seconds; (g) resin-based sealant (Fluroshield, Dentsply, Rio de Janeiro, Brazil) applied and light cured for 20 seconds; (h) occlusion checked and adjusted when necessary.

The teeth from the control group were restored according to the following protocol: (a) occlusal surface cleaned with pumice; (b) local anesthesia applied; (c) rubber dam applied; (d) cavity opened in enamel with a diamond bur in high speed, caries lesion completely removed in the enamel/dentin junction, and dentinal caries lesion partially removed with hand instruments until the dentin started to become 'firm and leathery' [29]; (e) 37\% phosphoric acid applied in the cavity for 15 seconds; (f) surface rinsed and dried; ( $\mathrm{g}$ ) adhesive system (Adper Single Bond 2, 3 M ESPE, Saint Paul, USA) applied, following the manufacturer's instructions and light cured for 20 seconds; (h) restoration with composite resin (Z250, 3 M ESPE, Saint Paul, USA), using the incremental technique until cavity was filled and light cured of each increment for 20 seconds; (i) occlusion checked and adjusted when necessary.

\section{Evaluation}

The follow-up period involved the evaluation of patients at 6,12 and 18 months after treatment and three examiners were responsible for the assessments. One of the examiners performed the clinical evaluations, while the other two carried out the radiographic evaluation.

The marginal integrity of sealants and restorations were assessed clinically by one examiner trained by a "golden standard" evaluator regarding the evaluation criteria $[30,31]$. In order to calculate the intra examiner concordance, 15 patients involved in the research were re-evaluated with an interval of two weeks (kappa intra value $=1.00)$. The scores for clinical assessment were: partial loss and total loss (failure) or total retention (success). When integrity failures were found during the follow-up visits, the re-application of the sealant or restoration-repair was done, however the related tooth was considered as a failure in the subsequent clinical analysis. The evaluation criteria for the clinical assessment at the follow-ups were the same for both groups.

Two trained and calibrated evaluators specialists in pediatric dentistry, who underwent four hours of specific training with radiographs, provided by a "gold standard" examiner, evaluated the caries lesion progression radiographically (kappa inter value $=0.85$ ). The outcome variable was the caries progression status (absence or presence of caries progression). The examiners assessed the radiographs through paired evaluations comparing two by two, blinded regarding chronological order of the radiographs and without the aid of any magnification loops. In cases of disagreement between the evaluators, a third examiner made the final decision.

\section{Statistical analysis}

All data were recorded in individual forms. The chi-square test was used to verify the distribution of characteristics variables of the sample among the groups. Fisher exact test was used to analyze the statistical differences in clinical retention and radiographic changes between the groups in the three follow-up assessments. The survival rate of each treatment was estimated by Kaplan-Meier analyses. The logistic regression test was used to evaluate the association among characteristics variables and the outcome. The level of significance considered for all tests was 5\%.

\section{Results}

Of the 36 children (mean age $=7$ years) who participate in the study, $16(44.4 \%)$ were female and 20 (55.6\%) were male. The children were randomly allocated, and $17(47.2 \%)$ of them had their cavities sealed, without removing caries tissue and $19(52.8 \%)$ received restorative treatment with composite resin, after partial dentinal caries removal was performed; 14 (39.9\%) were placed in the upper jaw and 22 (61.1\%) in the lower jaw; 19 $(52.8 \%)$ were in the left side and $17(47.2 \%)$ on the right side; 11 (30.5\%) were first primary molars and 25 (69.5\%) were second primary molars. The chi-square test showed an equal distribution in both groups with regards to the characteristics variables of the sample (Table 1) $(p>0.05)$.

A CONSORT flow diagram (Figure 1) shows: number of children, number of sealants and restorations, number of presence or absence of patients at the three evaluation times. The results of the clinical and radiograph assessments from both groups are expressed in Table 2. After 18 months, only 2 drop-outs in the control group is registered. However, two children in the experimental group did not show up at the 6- and 12-month control examinations but were examined at the 12- and 18-month examination, respectively. Therefore, both patients were re-included in the study. A significant difference was found after 18 months with better results regarding the clinical examination for the control group. After 6, 12 and 18 months, none of the lesions in both groups showed progression (Table 2).

The logistic regression test was applied to test the association among patient's characteristics variables and the outcome, and showed no association between any variable tested (gender, age, $1^{\text {st }}$ or $2^{\text {nd }}$ molar, upper or lower jaw and left or right side) and sealant failure.

Figure 2 shows Kaplan-Meier survival estimates curve in which a higher longevity of composite resin restorations (control group) can be observed, when compared to sealant application (experimental group). Log rank test 
Table 1 Distribution of the participating children according to treatment protocols

\begin{tabular}{|c|c|c|c|c|c|c|c|c|c|c|}
\hline & \multicolumn{2}{|c|}{ Age (yrs) } & \multicolumn{2}{|c|}{ Gender } & \multicolumn{2}{|c|}{ Jaw } & \multicolumn{2}{|c|}{ Jaw side } & \multicolumn{2}{|c|}{ Molar } \\
\hline & Mean & Range & Boys (n) & Girls (n) & Upper (n) & Lower $(n)$ & Right (n) & Left $(n)$ & $1^{\text {st }}$ molar $(n)$ & $2^{\text {nd }} \operatorname{molar}(n)$ \\
\hline Sealant application & 6.7 & $4-9$ & 9 & 8 & 4 & 13 & 11 & 6 & 7 & 10 \\
\hline Restorative treatment & 7.3 & $4-9$ & 11 & 8 & 10 & 9 & 8 & 11 & 4 & 15 \\
\hline
\end{tabular}

Chi-square test showed an equal distribution in both groups with regards to the characteristics variables of the sample ( $p>0.05)$.

$n$ number of children.

indicated a significant difference between the groups $(\mathrm{p}=0.0053)$.

\section{Discussion}

The hypothesis of this study stated that more caries progression in the experimental group was expected; however this hypothesis can be rejected due to the results (Table 2). Thus, over 18 months there is no difference in caries progression irrespective of caries removal. The lack of caries progression observed in the sealed teeth may be attributed to the fact that all molars presenting sealant failure were re-sealed, enabling the patient to control the biofilm and consequently arresting the caries progression [32]. Sealing may be an effective approach for treating cavitated occlusal caries with radiographic lesion penetration into the outer half of the dentin in primary molars;

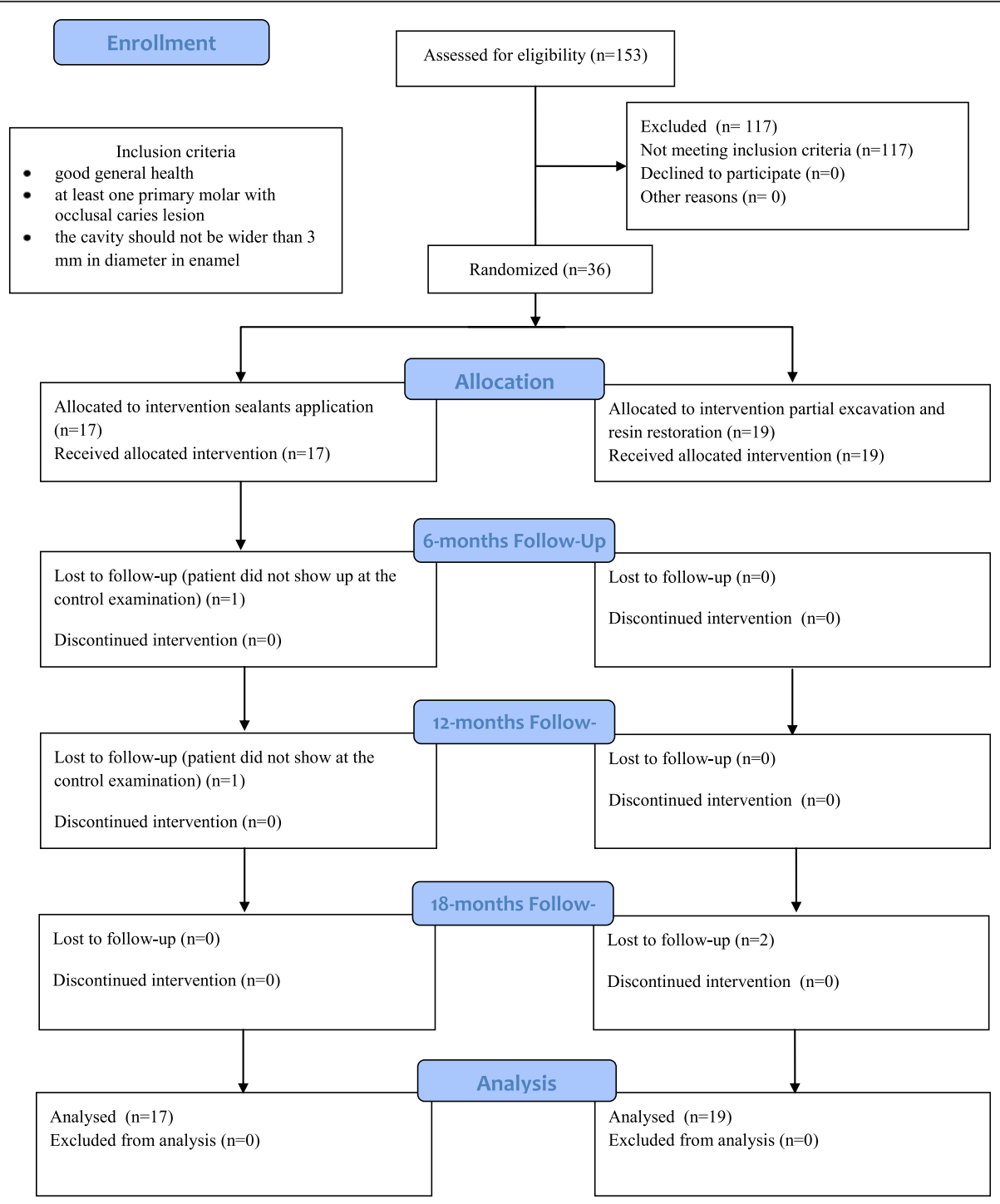

Figure 1 Consort flow diagram of the trial. $n$ number of children. 
Table 2 Clinical and radiographic results after 6, 12 and 18 months assessments

\begin{tabular}{|c|c|c|c|c|c|c|}
\hline & \multicolumn{4}{|c|}{ Clinical assessment } & \multicolumn{2}{|c|}{ Radiographic assessment } \\
\hline & $n$ & Success & Failure & $p$ & Absence of caries progression & Presence of caries progression \\
\hline \multicolumn{7}{|c|}{ Sealant application } \\
\hline 6 months & 16 & $14(87.5 \%)$ & $2(12.5 \%)$ & 0.23 & $16(100 \%)$ & 0 \\
\hline 12 months & 16 & $12(75.0 \%)$ & $4(25.0 \%)$ & 0.05 & $16(100 \%)$ & 0 \\
\hline 18 months & 17 & $11(64.7 \%)$ & $6(35.3 \%)$ & $0.0025^{*}$ & $17(100 \%)$ & 0 \\
\hline \multicolumn{7}{|c|}{ Restorative treatment } \\
\hline 6 months & 19 & $19(100 \%)$ & 0 & & 19 (100\%) & 0 \\
\hline 12 months & 19 & $19(100 \%)$ & 0 & & $19(100 \%)$ & 0 \\
\hline 18 months & 17 & 17 (100\%) & 0 & & 17 (100\%) & 0 \\
\hline
\end{tabular}

* Significance tested by Fisher's exact test.

No statistical analysis was performed for radiographic assessment because there were no cases of caries progression in both groups. $n$ number of children.

however, the results should be taken with caution because the sample size is limited in both experimental and control group.

In the same way as observed for the sealed teeth, the restored teeth showed caries arrestment. This was, in fact, expected, since the lesion was also isolated from the biofilm formation by restorative material. However, there is a risk of removing sound tooth substrate, when a tooth is treated by a restorative approach, while, the procedure for sealing is much less invasive. Furthermore, sealing dental caries offers the advantage of being less time-consuming than conventional restorative procedures. For this reason, sealing caries lesions in primary molars might be beneficial in treating non-cooperative children.

Another point of discussion is the use of adhesive system prior sealant application. This approach can be an alternative to increase the adhesion [33] and decrease microleakage in case of cavitaded occlusal lesions [34-38], as well as decline clinically the risk of failures of the sealants, especially in occlusal surfaces [35] and enhance the retention and longevity of this material [39]. In our study we used a conventional adhesive system prior sealant application in order to achieve better retention of the material in caries lesions that reached dentin, a more humid substrate that could negatively influence the retention results.

In our study, the teeth that had partial loss of the material had the occlusal surface re-sealed. The re-treatment was performed due to Ethical reasons; however as there were no cases of caries progression, these teeth were considered in subsequent radiograph evaluations. According to Handelman et al. [23], the treatment with sealants is efficient while the material is adhered to the tooth surface and the follow-up of teeth treated with sealants

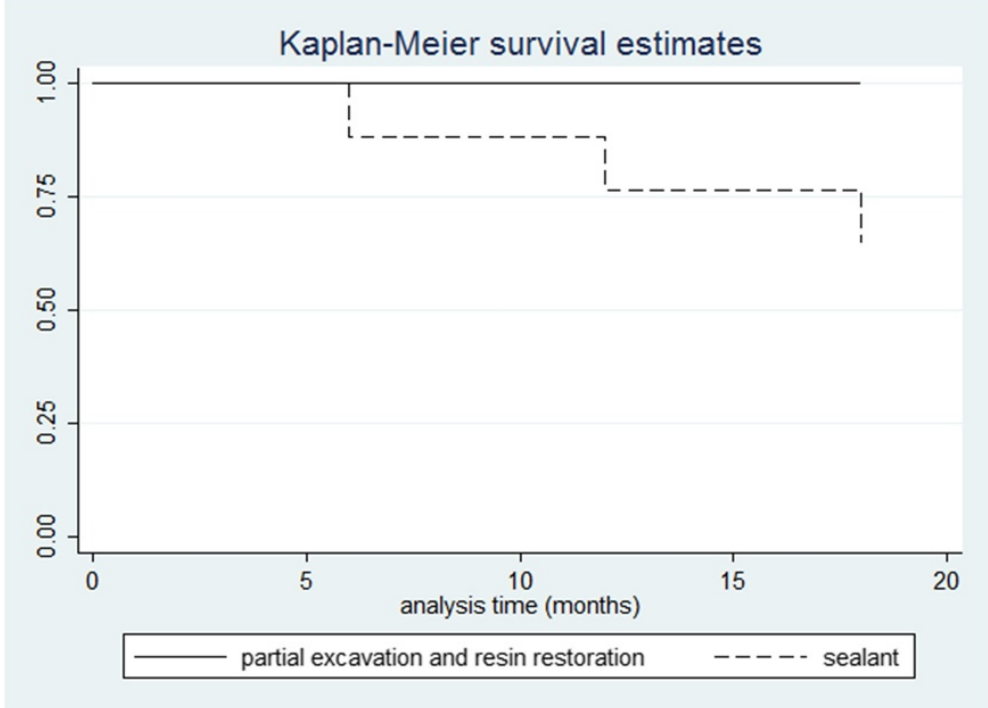

Figure 2 Kaplan-Meier survival curves for the clinical evaluation. Log-rank, $p=0.0053$. 
involves clinical and radiograph evaluation to assess the marginal integrity of the material and the arrestment of the lesion. Yet, according to Bakhshandeh et al. [11], the application of resin-based sealants on occlusal dentin lesions can postpone and even avoid conventional excavation and restoration of these lesions, as long as the sealant is intact and tight to the tooth. In these cases, even though the conventional restorative treatment may be necessary in the future, the prognosis for the individual tooth will be increased due to the postponement of a more invasive approach.

Nevertheless, we acknowledge the limits of our study as having a small sample size and a limited time of evaluation; however according to Hackshaw [40] there is nothing wrong with conducting well-designed small studies; they just need to be interpreted carefully. Yet, in our study sample power was calculated and resulted in 0.9 , which is considered as a strong effect. As the effect size is based on the difference between the means, it is expected that for a greater effect, the sample size required will be smaller. As this study was conducted on a sample with high caries experience, and the study period was only 18 months, its value in terms of external validity might be limited. Nevertheless, the arrestment of lesions was observed in $100 \%$ of cases in a population with high experience of caries, so it might also result in caries arrestment in a population with average caries experience, and for longer times. But this hypothesis needs to be confirmed.

Systematic reviews $[41,42]$ concluded that there was no evidence to justify the complete caries lesion excavation and partial caries tissue removal was recommended, including the maintenance of infected dentin in cases whose removal would increase the risk of pulp exposure. Thus, both systematic reviews available in the literature support the hypothesis that there is no need for complete removal of caries dentin towards the pulp. In our study, the control group was characterized by the partial caries removal and in all cases we observed arrested lesion. For that reason, our results support the theory that biofilm is responsible for caries lesions progression [3]. Therefore, the clinician should have in mind that restorative treatment aim to provide an adequate filling, giving the patient conditions to remove biofilm which leads to caries lesion arrestment [43]. Systematic reviews focused on sealing pit and fissures do not include caries lesions in dentin [2,5-7]. On the other hand, several studies have shown that by sealing the occlusal surface, it is possible to arrest dentinal caries [8-11,21-25]. However, most of these studies were performed in permanent teeth and the simple extrapolation of results obtained in previous studies with permanent teeth is not appropriate, since the primary teeth have individual physical and structural characteristics. The enamel in primary teeth is thinner and less mineralized than in permanent teeth, therefore the primary teeth has a higher rate of caries progression [44]. Based on our results, we can infer that there is no difference in caries progression when caries lesions in the outer half of dentin of primary teeth were treated with composite resin restoration or with resin-based sealant. Based on this, we can assume that there is no need of any caries tissue removal for arresting cavitated lesions located in the outer half of dentin in primary teeth.

\section{Conclusion}

In conclusion, although the control group has presented less restoration failures, both treatments are similar in arresting the caries progression.

\section{Competing interests}

The authors declare that they have no competing interests.

\section{Authors' contributions}

$\mathrm{DH}$ wrote the study protocol, performed literature review, clinical treatments and supervised evaluations and wrote the first draft of the manuscript. CCB made contributions during study protocol writing, supervised clinical treatments and made manuscript revisions, FMM performed the statistical analysis and made contributions to the interpretation of the results and manuscript revisions, MMB made contributions to the interpretation of the results and manuscript revisions, JCPI made contributions during study protocol writing, supervised clinical treatments and evaluations, DPR made contributions during study protocol writing, literature review, supervised clinical treatments and evaluations, made contributions to statistical analysis, as well as to the interpretation of the results and manuscript revisions. All authors have read and approved the final version of the manuscript.

\section{Acknowledgements}

We would like to thank the participants of the Post-Graduation in Pediatric Dentistry Seminar from FOUSP for the critical comments put forth. The study was supported by the Conselho Nacional de Desenvolvimento Científico e Tecnológico (CNPq ) and Fundação de Amparo à Pesquisa do Estado de São Paulo (FAPESP).

\section{Author details}

'Orthodontics and Pediatric Dentistry Department, Dental School, University of São Paulo - USP, Av. Lineu Prestes, São Paulo, SP 2227, Brazil. ${ }^{2}$ Department of Conservative Dentistry, Academic Centre for Dentistry Amsterdam - ACTA, Amsterdam, The Netherlands.

Received: 10 December 2013 Accepted: 22 May 2014

Published: 28 May 2014

\section{References}

1. Pitts NB: Are we ready to move from operative to non-operative/preventive treatment of dental caries in clinical practice? Caries Res 2004, 38:294-304.

2. Beauchamp J, Caufield PW, Crall JJ, Donly K, Feigal R, Gooch B, Ismail A, Kohn W, Siegal M, Simonsen R: Evidence-based clinical recommendations for the use of pit-and-fissure sealants: a report of the American Dental Association Council on Scientific Affairs. J Am Dent Assoc 2008, 139:257-268.

3. Kidd EA: How 'clean' must a cavity be before restoration? Caries Res 2004, 38:305-313.

4. Kervanto-Seppälä S, Pietilä I, Meurman JH, Kerosuo E: Pit and fissure sealants in dental public health - application criteria and general policy in Finland. BMC Oral Health 2009, 9:5.

5. Azarpazhooh A, Main PA: Pit and fissure sealants in the prevention of dental caries in children and adolescents: a systematic review. J Can Dent Assoc 2008, 74:171-177.

6. Griffin SO, Oong E, Kohn W, Vidakovic B, CDC Dental Sealant Systematic Review Work Group, Gooch BF, Bader J, Clarkson J, Fontana MR, Meyer DM, Rozier RG, Weintraub JA, Zero DT: The effectiveness of sealants in managing caries lesions. J Dent Res 2008, 87:169-174. 
7. Oong EM, Griffin SO, Kohn WG, Gooch BF, Caufield PW: The effect of dental sealants on bacteria levels in caries lesions: a review of the evidence. J Am Dent Assoc 2008, 139:271-278.

8. Handelman SL, Washburn F, Wopperer P: Two-year report of sealant effect on bacteria in dental caries. J Am Dent Assoc 1976, 93:967-970.

9. Jensen $\mathrm{OE}$, Handelman SL: Effect of an autopolymerizing sealant on viability of microflora in occlusal dental caries. Scand J Dent Res 1980, 88:382-388.

10. Mertz-Fairhurst EJ, Call-Smith KM, Shuster GS, Williams JE, Davis QB, Smith CD, Bell RA, Sherrer JD, Myers DR, Morse PK: Clinical performance of sealed composite restorations placed over caries compared with sealed and unsealed amalgam restorations. J Am Dent Assoc 1987, 115:689-694.

11. Bakhshandeh A, Qvist V, Ekstrand KR: Sealing occlusal caries lesions in adults referred for restorative treatment: $2-3$ years of follow-up. Clin Oral Investig 2011, 16:521-529.

12. Ricketts D: Deep or partial caries removal: which is best? Evid Based Dent 2008, 9:71-72.

13. Ricketts $D$, Lamont $T$, Innes NP, Kidd E, Clarkson JE: Operative caries management in adults and children. Cochrane Database Syst Rev 2013, 28, CD003808

14. Lula EC, Monteiro-Neto V, Alves CM, Ribeiro CC: Microbiological analysis after complete or partial removal of carious dentin in primary teeth: a randomized clinical trial. Caries Res 2009, 43:354-358.

15. Kühnisch J, Mansmann U, Heinrich-Weltzien R, Hickel R: Longevity of materials for pit and fissure sealing-results from a meta-analysis. Dent Mater 2012, 28:298-303.

16. Feigal RJ, Quelhas I: Clinical trial of a self-etching adhesive for sealant application: success at 24 months with Prompt L-Pop. Am J Dent 2003, 16:249-251.

17. Ram D, Mamber E, Fuks AB: Clinical performance of a non-rinse conditioning sealant in three paediatric dental practices: a retrospective study. Int J Paediatr Dent 2005, 15:61-66.

18. Borges BC, de Souza BJ, Braz R, Montes MA, de Assunção Pinheiro IV: Arrest of non-cavitated dentinal occlusal caries by sealing pits and fissures: a 36-month, randomised controlled clinical trial. Int Dent J 2012, 62:251-255.

19. Lam A: Increase in utilization of dental sealants. J Contemp Dent Pract 2008, 9:81-87.

20. Splieth CH, Ekstrand KR, Alkilzy M, Clarkson J, Meyer-Lueckel H, Martignon S, Paris S, Pitts NB, Ricketts DN, van Loveren C: Sealants in dentistry: outcomes of the ORCA Saturday afternoon symposium. Caries Res 2010, 44:3-13.

21. Handelman SL, Buonocore MG, Hersck DJ: A preliminary report on the effect of fissure sealant on bacteria in dental caries. J Prosthet Dent 1972 27:390-392.

22. Going RE, Loesche WJ, Grainger DA, Syed SA: The viability of microorganisms in carious lesions five years after covering with a fissure sealant. J Am Dent Assoc 1978, 97:455-462.

23. Handelman SL, Leverett DH, Iker HP: Longitudinal radiographic evaluation of the progress of caries under sealants. J Pedod 1985, 9:119-126.

24. Mertz-Fairhurst EJ, Curtis JW Jr, Ergle JW, Rueggeberg FA, Adair SM: Ultraconservative and cariostatic sealed restorations: results at year 10 . J Am Dent Assoc 1998, 129:55-66.

25. Mertz-Fairhurst EJ, Schuster GS, Williams JE, Fairhurst CW: Clinical progress of sealed and unsealed caries. Part I: depth changes and bacterial counts. J Prosthet Dent 1979, 42:521-526.

26. Ismail Al, Sohn W, Tellez M, Amaya A, Sen A, Hasson H, Pitts NB: The International Caries Detection and Assessment System (ICDAS): an integrated system for measuring dental caries. Community Dent Oral Epidemiol 2007, 35:170-178.

27. Nyvad B, Machiulskiene V, Baelum V: Reliability of a new caries diagnostic system differentiating between active and inactive caries lesions. Caries Res 1999, 33:252-260.

28. SB Brasil. http://189.28.128.100/dab/docs/geral/projeto_sb2010_relatorio_ final.pdf.

29. Hilton TJ, Summitt JB: Pulpal Considerations. In Operative Dentistry. Edited by Summitt JB, Robbins JW, Schwartz RS. Chicago: Quintessence Publishing Co; 2000:103.

30. Houpt M, Fukus A, Eidelman E: The preventive resin (composite resin/ sealant) restoration: nine-year results. Quintessence Int 1994, 25:155-159.

31. Houpt M, Shey Z: The effectiveness of a fissure sealant after six years. Pediatr Dent 1983, 5:104-106

32. Kidd EAM, van Amerongen JP, van Amerongen WE: The role of operative dentistry in caries control. In Dental Caries: The Disease and its Clinical
Management. 2nd edition. Edited by Fejerskov O, Kidd EAM. Oxford: Blackwell Munksgaard; 2008:356-365.

33. Hitt JC, Feigal RJ: Use of a bonding agent to reduce sealant sensitivity to moisture contamination: an in vitro study. Pediatr Dent 1992, 14:41-46.

34. Borem LM, Feigal RJ: Reducing microleakage of sealants under salivary contamination: digital-image analysis evaluation. Quintessence Int 1994, 25:283-289

35. Feigal RJ, Musherure P, Gillespie B, Levy-Polack M, Quelhas I, Hebling J: Improved sealant retention with bonding agents: a clinical study of two-bottle and single-bottle systems. J Dent Res 2000, 79:1850-1856.

36. Hebling J, Feigal RJ: Use of one-bottle adhesive as an intermediate bonding layer to reduce sealant microleakage on saliva-contaminated enamel. Am J Dent 2000, 13:187-191.

37. Cehreli ZC, Gungor HC: Quantitative microleakage evaluation of fissure sealants applied with or without a bonding agent: results after four-year water storage in vitro. J Adhes Dent 2008, 10:379-384.

38. Hevinga MA, Opdam NJ, Frencken JE, Bronkhorst EM, Truin GJ: Can caries fissures be sealed as adequately as sound fissures? J Dent Res 2008, 87:495-498.

39. Burbridge L, Nugent $Z$, Deery $C$ : A randomized controlled trial of the effectiveness of a one-step conditioning agent in fissure sealant placement: 12 month results. Eur Arch Paediatr Dent 2007, 8:49-54.

40. Hackshaw A: Small studies: strengths and limitations. Eur Respir J 2008 32:1141-1143.

41. Ricketts DN, Kidd EA, Innes N, Clarkson J: Complete or ultraconservative removal of decayed tissue in unfilled teeth. Cochrane Database Syst Rev 2006, 19: CD003808. Update in: Cochrane Database Syst Rev 2013 3:CD003808

42. Thompson V, Craig RG, Curro FA, Green WS, Ship JA: Treatment of deep carious lesions by complete excavation or partial removal: a critical review. J Am Dent Assoc 2008, 139:705-712.

43. Kidd EA: Clinical threshold for carious tissue removal. Dent Clin North Am 2010, 54:541-549.

44. Koutsi V, Noonan RG, Horner JA, Simpson MD, Matthews WG, Pashley DH: The effect of dentin depth on the permeability and ultrastructure of primary molars. Pediatr Dent 1994, 16:29-35.

doi:10.1186/1472-6831-14-58

Cite this article as: Hesse et al: Sealing versus partial caries removal in primary molars: a randomized clinical trial. BMC Oral Health 2014 14:58.

\section{Submit your next manuscript to BioMed Central and take full advantage of:}

- Convenient online submission

- Thorough peer review

- No space constraints or color figure charges

- Immediate publication on acceptance

- Inclusion in PubMed, CAS, Scopus and Google Scholar

- Research which is freely available for redistribution

Submit your manuscript at www.biomedcentral.com/submit
C Biomed Central 